\title{
What do we mean by individual capacity strengthening for primary health care in low- and middle-income countries? A systematic scoping review to improve conceptual clarity
}

Mairéad Finn ${ }^{1,2^{*}}$, Brynne Gilmore ${ }^{3}$, Greg Sheaf ${ }^{4}$ and Frédérique Vallières ${ }^{1}$

\begin{abstract}
Background: Capacity strengthening of primary health care workers is widely used as a means to strengthen health service delivery, particularly in low- and middle-income countries. Despite the widespread recognition of the importance of capacity strengthening to improve access to quality health care, how the term 'capacity strengthening' is both used and measured varies substantially across the literature. This scoping review sought to identify the most common domains of individual capacity strengthening, as well as their most common forms of measurement, to generate a better understanding of what is meant by the term 'capacity strengthening' for primary health care workers.

Methods: Six electronic databases were searched for studies published between January 2000 and October 2020. A total of 4474 articles were screened at title and abstract phase and 323 full-text articles were reviewed. 55 articles were ultimately identified for inclusion, covering various geographic settings and health topics.

Results: Capacity strengthening is predominantly conceptualised in relation to knowledge and skills, as either sole domains of capacity, or used in combination with other domains including self-efficacy, practices, ability, and competencies. Capacity strengthening is primarily measured using pre- and post-tests, practical evaluations, and observation. These occur along study-specific indicators, though some pre-existing, validated tools are also used.

Conclusion: The concept of capacity strengthening for primary health care workers reflected across a number of relevant frameworks and theories differs from what is commonly seen in practice. A framework of individual capacity strengthening across intra-personal, inter-personal, and technical domains is proposed, as an initial step towards building a common consensus of individual capacity strengthening for future work.
\end{abstract}

Keywords: Scoping review, Capacity strengthening, Capacity building, Low- and middle-income countries, Primary health care workers

\section{Introduction}

Capacity strengthening for primary health care workers is widely relied upon as a strategy for improving health worker performance, for strengthening health systems,

*Correspondence: mairead.finn@tcd.ie

${ }^{1}$ Trinity Centre for Global Health, School of Psychology, Trinity College Dublin, Dublin, Ireland

Full list of author information is available at the end of the article and for overall quality improvement in the delivery of health services globally [1-4]. In this way, capacity strengthening interventions for human resources for health is considered an important mechanism to achieve Universal Health Coverage (UHC) under Workforce 2030, through the Global Strategy for Human Resources for Health [5, 6], and to support the implementation of the Sustainable Development Goals, articulated in Goal 17.9 [7]. In the context of these global frameworks, and original author(s) and the source, provide a link to the Creative Commons licence, and indicate if changes were made. The images or other third party material in this article are included in the article's Creative Commons licence, unless indicated otherwise in a credit line to the material. If material is not included in the article's Creative Commons licence and your intended use is not permitted by statutory regulation or exceeds the permitted use, you will need to obtain permission directly from the copyright holder. To view a copy of this licence, visit http://creativecommons.org/licenses/by/4.0/. The Creative Commons Public Domain Dedication waiver (http://creativeco mmons.org/publicdomain/zero/1.0/) applies to the data made available in this article, unless otherwise stated in a credit line to the data. 
in recognition of the paramount importance of a strong workforce to strengthen health systems, there are substantial investments to build primary health worker capacity in low- and middle-income countries (LMICs). Strengthening health systems, including the workforce at primary level, is thus recognised as a vehicle through which to enhance quality of care for broader populations, particularly those most vulnerable or marginalised [6].

Broadly defined as the ability to carry out stated objectives [8], capacity is a coveted aspect of human capital. Capacity strengthening (also commonly referred to as capacity building) has been conceptualised as an ongoing process by which individuals, groups, organisations, and societies increase their ability to perform core functions, solve problems, define and achieve objectives, and understand and deal with development needs in a broad context and sustainable manner [9]. This process is reflected across a number of prevalent models or frameworks, which consider capacity strengthening as taking place across individual, organisational, community, societal and a broader 'systems' components [10, 11].

Capacity strengthening for health interventions tends to take place at the level of the individual, ranging from training individuals in leadership, strategic thinking, supervisory, financial, project, and performance management skills, to training on more technical subjects, including laboratory, clinical and non-clinical, surveillance, monitoring, and research skills [12, 13]. It also takes place at the level of the organisation (i.e. through improved partnership, leadership, or governance infrastructure) [2]; and at the level of the community (i.e. community health programming) $[14,15]$. A common inference however, is that intervening at one level (i.e. at the level of the individual primary health care worker) will subsequently result in observable changes within another level (i.e. organisational) $[16,17]$.

Despite efforts to map the theoretical underpinnings of capacity strengthening approaches [17], assessing or evaluating whether programmes designed to strengthen capacity effectively do so remains difficult, prompting some to call for the term to be considered and understood in more practical terms $[15,18]$. Moreover, the effects of capacity strengthening interventions on improved health outcomes are difficult to ascertain. According to Crisp et al. [16], evaluating capacity must consider that (i) capacity strengthening is a process and therefore evolves over time; (ii) aggregates of individual change may be insufficient to assess organisational or community level changes, and (iii) capacity strengthening may result in unintended consequences across other components. Similarly, Aroni [18] notes that the complexity and multi-disciplinary nature of capacity strengthening in practice poses inherent challenges when it comes to measuring changes in capacity. In response to the problem of measurement, others have attempted to conceptualise capacity strengthening in terms of its indicators, or domains [15]. Nevertheless, it remains unclear what domains are most commonly used in the literature where studies claim to have demonstrated an increase in individual capacity among primary health care workers.

\section{Study objectives}

Despite the frequent use of the term 'capacity strengthening' within the academic and implementation literature, and the widespread recognition of the importance of capacity strengthening in improving access to quality health care [19], there is substantial variation in how capacity strengthening is both interpreted and measured. Thus, and informed by the growing emphasis within programmes on 'capacity strengthening' approaches for primary health care workers and by the absence of an identified set of domains comprising 'capacity strengthening' at the level of the individual, the aims of this scoping review are twofold. Firstly, the study aimed to identify common domains of capacity strengthening for primary health care workers, assessed at the level of the individual. Specifically, we ask what domains are referred to, and in which combinations, in studies that aim to strengthen 'capacity' among primary health care workers? Second, we identify the methods used to measure and assess these domains. In achieving both of these aims, we offer insight into what is commonly understood as individual capacity strengthening for primary health care within LMICs.

\section{Methodology}

A systematic scoping review of the literature was carried out following procedures described by Arksey and O'Malley's [20] and Levac, Colquhoun and O'Brien [21]. Scoping review methodology was chosen because of the potential wide array of relevant literature, and because of the recognised value of scoping reviews in clarifying concepts or to investigate research conduct [22]. The current review included articles published from 2000-corresponding to the launch of the Millennium Development Goals - to October 2020. An initial search was conducted in July 2018, subsequently updated to October 2020. Both rounds of searching adhered to the same procedures, outlined below.

\section{Identifying relevant studies-inclusion and exclusion criteria}

The population was restricted to primary health care workers, conceptualised as any non-specialist health care worker providing health care at the first point of contact to the health system, for individuals and families in the community $[23,24]$. Included papers were further 
required to describe capacity strengthening interventions targeting the primary health care worker. Interventions specific to research capacity strengthening were excluded, as this has been extensively examined elsewhere [25]. Lastly, and given that capacity strengthening is recognised as a process taking place over time [16], only studies that measured changes in capacity were included. The review's full inclusion and exclusion criteria are summarised in Table 1.

\section{Identifying relevant studies-search strategy}

The search terminology included four categories: capacity strengthening, health care providers, primary care, and low- and middle-income countries. A subject librarian (GS) developed search strings for six electronic databases-CINAHL, Embase, MEDLINE, ProQuest Social Science Premium Collection, PsycINFO, and Scopuswhich were searched using various combinations of indexing and key search terms. Additional file 1 contains the search strings formatted for MEDLINE. The reference lists of all articles retrieved for full-text screening were also searched.

\section{Study selection}

Two researchers (MF, BG or FV) independently assessed studies, at both title and abstract and full-text screening phase. Any discrepancies between the two primary screening authors were brought forward to the third author for review. If unresolved, all three discussed the study together and came to an agreement.

\section{Data management, extraction and synthesis}

Returned studies were imported into EndNote, where duplicates were removed. Remaining articles were then compiled and screened in Covidence, a systematic review data management tool. A data extraction template was created in Microsoft Excel to capture information including the study characteristics, intervention characteristics, capacity strengthening domains and outcome measures. MF extracted the data for each included study and a second author (BG or FV) independently compared extractions for $20 \%$ of the articles for inter-rater reliability. The authors also discussed any cases where it was necessary to clarify decisions.

\section{Quality assessment}

The Mixed Methods Appraisal Tool (MMAT) [27] was applied to each article. MMAT has been used successfully for other systematic literature reviews [28] and was chosen for its ability to score studies of varying methodological traditions in a single coherent manner. Due to the nature of this review, the MMAT was not used to inform the interpretation of our findings, but is presented as a resource to readers who may wish to apply individual studies to their own practice.

\section{Results}

In total, 6078 articles were returned from the combined database searches, of which 1604 were duplicates. Of the 4474 screened at title and abstract phase, 323 were put through for full-text screening. 269 articles were excluded at full-text phase. An additional 21 articles were identified through snowballing, of which one was

Table 1 Inclusion and exclusion criteria

\begin{tabular}{|c|c|c|}
\hline & Inclusion criteria & Exclusion criteria \\
\hline Population & Primary health care workers & $\begin{array}{l}\text { Non-primary health care workers (i.e. specialists, consultants } \\
\text { researchers) }\end{array}$ \\
\hline Intervention & $\begin{array}{l}\text { Interventions that aimed to strengthen capacity at the individual } \\
\text { level }\end{array}$ & $\begin{array}{l}\text { Interventions aiming to strengthen capacity at organisational or } \\
\text { community level } \\
\text { Interventions aiming to build research capacity }\end{array}$ \\
\hline Context & $\begin{array}{l}\text { Low-income and lower-middle income countries as defined by } \\
\text { the World Bank at time of study [26] }\end{array}$ & $\begin{array}{l}\text { High-income and upper-middle income countries at time of } \\
\text { study }\end{array}$ \\
\hline Outcomes & $\begin{array}{l}\text { Studies must have assessed changes in capacity specifically at } \\
\text { the level of the individual }\end{array}$ & $\begin{array}{l}\text { Studies which intervened at the individual level, but which only } \\
\text { assessed changes outside of the individual level (i.e. organisa- } \\
\text { tional or community) }\end{array}$ \\
\hline Study design & $\begin{array}{l}\text { Studies must have a comparative element assessing capacity } \\
\text { at a minimum of two timepoints (i.e. pre-post) or using an } \\
\text { experimental design }\end{array}$ & Non-comparative or cross-sectional designs \\
\hline Date range & Published from 2000 & Published prior to 2000 \\
\hline Publication type & Research article & $\begin{array}{l}\text { Conference abstracts, conference proceedings, grey literature, } \\
\text { report }\end{array}$ \\
\hline Languages & All, though searching was primarily conducted in English & \\
\hline
\end{tabular}


included. A total of 55 articles were identified for inclusion. Figure 1 summarises the screening process.

\section{Article characteristics}

Primary health care workers in the sample studies included physicians, nurses, midwives, medical officers, community health workers, surveillance officers, clinical officers, as well as psychiatrists and disease control officers. Forty-nine capacity strengthening interventions took place in one national setting, two were set between twoor four-country contexts; and four were set across wider regions of the Middle East, Africa and South Asia. Interventions were implemented across a range of settings including rural communities, cities, district and primary

PRISMA 2009 Flow Diagram
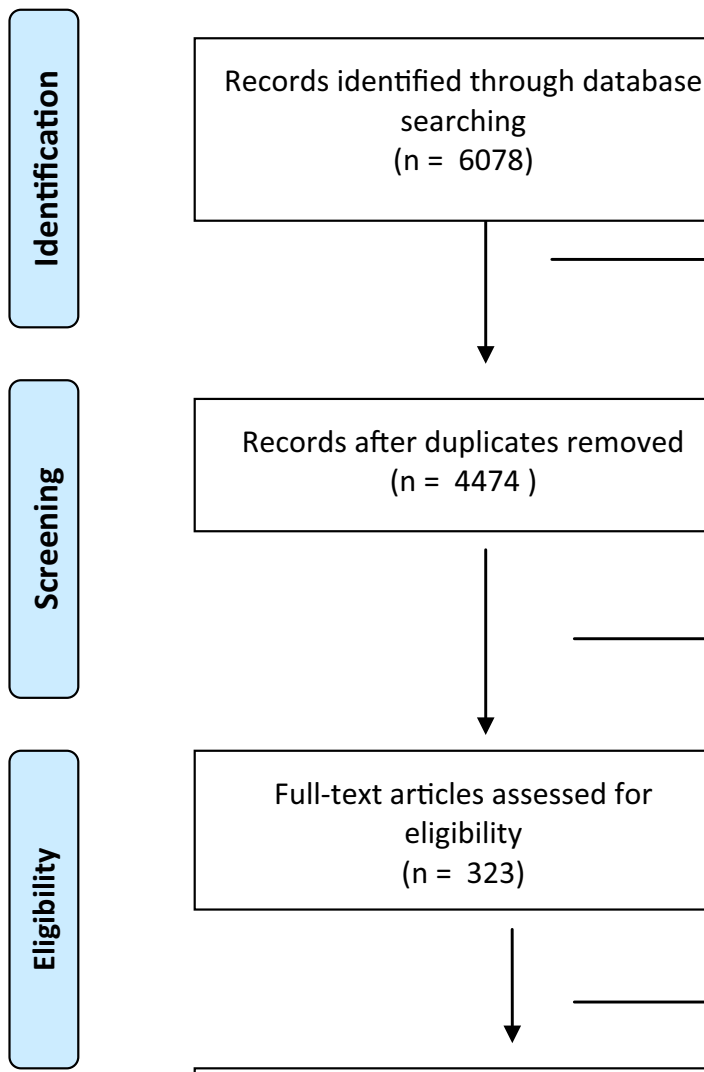

Full-text articles assessed for eligibility

$(n=323)$

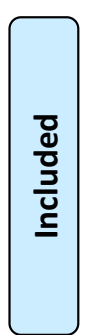

Selected articles

$(n=54)$


Excluded Study Type $(n=145)$

Excluded Method ( $n=76)$

Excluded Setting $(n=48)$

Less duplicates

$(n=1604)$

Records excluded after title and abstract review

$(n=4151)$

Full-text articles excluded, with reasons $(n=269)$

Articles identified from manual search

$(n=1)$

Included articles $(n=55)$

Fig. 1 PRISMA flow diagram 
health facilities, communities, as well as conferences and educational settings. Most studies $(n=46)$ were published after 2010, with 40 published between 2015 and 2020 , aligning to an increased focus on capacity strengthening resulting from the commencement of the SDGs.

Capacity strengthening interventions ranged from disease prevention and surveillance, to clinical, management and supervision interventions. Each study contained some form of training for primary health care workers with the duration of training ranging from 2.5 hours to a 4-year ongoing programme. Interventions employed an array of educational resources including manuals, activities at conferences and workshops, lectures and e-learning supports, mentorship, and case studies and role plays, overall encompassing both didactic and experiential learning. Additional file 2 contains the full table of included studies, their capacity strengthening topics and specific details on the approaches, components and measurements.

\section{Quality assessment}

MMAT resulted in the identification of 19 studies being deemed as low quality. The majority of studies complied with the quality criteria with 14 studies meeting all five and 22 studies meeting four of five. A detailed presentation of the ratings of each of the included studies, across the five criteria, is available in Additional file 3.

\section{Objective 1: domains of capacity strengthening}

Domains of capacity strengthening were extracted based on the terminology used in each study. Sixteen domains of capacity strengthening were identified across the sample of 55 studies: knowledge, skills, timeliness, confidence, abilities, leadership, motivation, self-efficacy, commitment, resources, attitudes, practices, competence, awareness, professional satisfaction and professional quality of life. Table 2 provides a summary of these 16 domains identified, including where they were used in combination with other domains (i.e. co-domains).

Within the sample, 16 studies defined capacity strengthening as a single domain. These studies measured knowledge $(n=13)$, skills $(n=2)$ and practice $(n=1)$. Nineteen studies used a combination of two domains, 14 used three domains, and the remaining used four $(n=5)$ and five $(n=1)$. Across the full sample, the most commonly reported domain of capacity strengthening was knowledge $(n=51)$. Knowledge was most frequently strengthened alongside skills $(n=18)$, attitude $(n=10)$, confidence $(n=8)$, practice $(n=6)$ and self-efficacy $(n=6)$. Skills were the second most recorded domain $(n=25)$, similarly most frequently strengthened alongside knowledge $(n=18)$, followed by confidence $(n=4)$. Knowledge or skills were present in 52 of 55 studies, either alone or in combination with other domains.

Domains of capacity were strengthened across a range of aspects of primary health care. Knowledge as a sole domain was strengthened primarily on clinical and technical subjects, with a more limited number of studies focusing on management and supervision. For example, Citraningtyas et al. [29] built knowledge to enhance mental health workers' understanding of how to provide assistance to children and adolescents in disaster affected areas in Indonesia. Strengthening of skills as the sole domain tended towards strengthening leadership and management skills among supervisors [30, 31]. In the 18 studies which measured skills alongside knowledge, capacity strengthening was conceptualised as both increases in content knowledge and observed practice, over a range of topics ranging from health promotion [32] to disease surveillance [33], and infection control [34]. One study related to ability to coach clinical skills and quality improvement [35], and another to the management of substance use conditions [36], with all other studies related to more technical skills, such as breast ultrasound interpretation [37], surveillance [33] and neonatal continuous positive airway pressure [38].

Thirteen studies assessing the domains of self-efficacy or confidence were applied to strengthen leadership, managerial or teaching capacity [39-42]; working with patients [43-46]; and for the provision of care, such as treatment for non-communicable disease [47], anti-retroviral therapy [45], and providing mental health care [48-51], a topic which has become prevalent in more recent years.

\section{Objective 2: measurements of capacity strengthening}

Changes in individual capacity were measured using a range of methods including pre-intervention and postintervention objective knowledge assessments $(n=37)$, pre- and post-subjective assessments $(n=21)$, and observation or practical assessment $(n=20)$, among others. The various tools used to measure the strengthening of capacity are summarised in Table 3, according to each domain(s). Many studies contained a combination of approaches [37, 40, 46-48, 50, 52-64]. Research designs included pre- and post-survey measures, quasiexperimental, prospective and retrospective evaluations, cluster randomised trial components, and participatory needs assessments.

Capacity strengthening for individual domains was primarily measured via objective measures $(n=57)$, either through testing of percentage increase in knowledge $(n=37)$ or through the direct observation of a specific task $(n=20)$. Change in knowledge was also assessed using subjective, self-report measures $(n=9)$, most 
Table 2 Domains of individual capacity strengthening

\begin{tabular}{|c|c|c|}
\hline \multicolumn{3}{|c|}{ Objective 1: domains of individual capacity strengthening } \\
\hline Domain & Articles & Co-domains \\
\hline Knowledge $(n=51)$ & $\begin{array}{l}\text { See Additional file } 4 \\
n=13 \text { measure knowledge as the sole domain }\end{array}$ & $\begin{array}{l}\text { Total with co-domains }(n=38) \\
\text { Skills }(n=18) \\
\text { For remaining, see domains below }\end{array}$ \\
\hline Skills $(n=25)$ & $\begin{array}{l}\text { See Additional File } 4 \\
n=2 \text { measure skills as the sole domain }\end{array}$ & $\begin{array}{l}\text { Total with co-domains ( } n=23) \\
\text { Knowledge }(n=18) \\
\text { For remaining, see domains below }\end{array}$ \\
\hline \multirow[t]{11}{*}{ Attitude $(n=11)$} & Hofmann-Broussard et al. [48] & Knowledge, confidence \\
\hline & Kamiru et al. [45] & Knowledge, self-efficacy \\
\hline & Kohrt et al. [64] & Knowledge, clinical competence \\
\hline & Liautaud et al. [78] & Knowledge, skills, practice \\
\hline & Minh et al. [58] & Knowledge, practice \\
\hline & Sijbrandij et al. [50] & Knowledge, skills, confidence, professional satisfaction \\
\hline & Spagnolo et al. [51] & Knowledge, self-efficacy, practice \\
\hline & Taieb et al. [66] & Knowledge, practice \\
\hline & Tharkar et al. [62] & Knowledge, behaviour \\
\hline & Werdenberg et al. [72] & Practice \\
\hline & Williams et al. [44] & Knowledge, self-confidence \\
\hline \multirow[t]{8}{*}{ Confidence $(n=8)$} & Bemah et al. [46] & Knowledge, skills \\
\hline & Blignault et al. [73] & Knowledge, skills \\
\hline & Edwards et al. [43] & Knowledge, skills, ability \\
\hline & Hofmann-Broussard et al. [48] & Knowledge, attitude \\
\hline & Mehrotra et al. [49] & Knowledge, self-efficacy \\
\hline & Sharma et al. [42] & Knowledge \\
\hline & Sijbrandij et al. [50] & Knowledge, skills, attitude, professional satisfaction \\
\hline & Williams et al. [44] & Knowledge, attitude \\
\hline \multirow[t]{8}{*}{ Practice $(n=8)$} & Burnett et al. [70] & - \\
\hline & Echeverri et al. [79] & Knowledge, attitude, skills \\
\hline & Imani et al. [69] & Knowledge \\
\hline & Liautaud et al. [78] & Knowledge, attitude, skills \\
\hline & Minh et al. [58] & Knowledge, attitude \\
\hline & Taieb et al. [66] & Knowledge, attitude \\
\hline & Spagnolo et al. [51] & Knowledge, attitude, self-efficacy \\
\hline & Werdenberg et al. [72] & Attitude \\
\hline \multirow[t]{6}{*}{ Self-efficacy $(n=6)$} & Bikinesi et al. [41] & Knowledge, professional satisfaction \\
\hline & Davila et al. [47] & Knowledge, skills \\
\hline & Kamiru et al. [45] & Knowledge, attitude \\
\hline & Mehrotra et al. [49] & Knowledge, confidence \\
\hline & Mutale et al. [39] & Knowledge, motivation \\
\hline & Spagnolo et al. [51] & Knowledge, attitude, practice \\
\hline \multirow[t]{3}{*}{ Abilities $(n=3)$} & Chaoniyom et al. [53] & Knowledge, leadership, motivation \\
\hline & Edwards et al. [43] & Knowledge, skill, confidence \\
\hline & Sennun et al. [67] & Knowledge \\
\hline \multirow[t]{2}{*}{ Motivation $(n=2)$} & Chaoniyom et al. [53] & Knowledge, leadership, ability \\
\hline & Mutale et al. [39] & Knowledge, self-efficacy \\
\hline Commitment $(n=1)$ & Kim et al. [55] & Knowledge, skills, resources \\
\hline \multirow[t]{2}{*}{ Competence $(n=2)$} & Kohrt et al. [64] & Knowledge, attitude \\
\hline & Mazia et al. [56] & Knowledge, skills \\
\hline Leadership $(n=1)$ & Chaoniyom et al. [53] & Knowledge, ability, motivation \\
\hline Resources $(n=1)$ & Kim et al. [55] & Knowledge, skills, commitment \\
\hline
\end{tabular}


Table 2 (continued)

\begin{tabular}{lll}
\hline Objective 1: domains of individual capacity strengthening & \\
\hline Domain & Articles & Co-domains \\
\hline Timeliness $(n=1)$ & André et al. [68] & Knowledge \\
Awareness $(n=1)$ & Oladele et al. [80] & Skills \\
Professional satisfaction $(n=1)$ & Bikinesi et al. [41] & Knowledge, self-efficacy \\
Professional quality of life $(n=1)$ & Sijbrandij et al. [50] & Knowledge, skills, attitude, confidence \\
\hline
\end{tabular}

commonly determined by asking individuals whether they had perceived a change in knowledge as a result of a capacity strengthening intervention. Two studies measured skills alone, one using a subjective measure [30] and the other using an objective measure [31]. For the most part, skills were measured directly through observation or practice assessment $(n=11)$, but in some cases, the acquisition of skills through practice was inferred from the acquisition of knowledge [58, 65, 66]. Ameme et al. [65] examined the impact of knowledge gained on practice and Minh et al. [58] recognised that knowledge does not always translate into practice.

Attitudes were largely measured through self-evaluation $(n=4)$ and vignettes $(n=3)$, but also through practice [62]. Confidence was always measured through pre-post self-report assessments $(n=8)$.

Twelve studies used multiple methods including a combination of subjective and objective measures of capacity. For example, Sennun et al. [67] employed a combination of subjective, self-rated assessment and objective observation to measure the effect of supervision models on the knowledge and ability of Health Officers and District Level Supervisors. In contrast, Davila et al. [47] used objective measures of knowledge and subjective, participant self-report measures to assess strengthening in the multiple domains of skills and self-efficacy for treating non-communicable diseases. Validated scales were used in 19 studies, including the Nursing Best Practice Guidelines [43]; Objective Structured Clinical Assessment (OSCA) [61]; and the mental health Global Action Programme (mhGAP) Knowledge Assessment and Attitude Scale [49-51, 64]. Full details of these validated tools are in Additional file 4.

The majority of studies $(n=36)$ measured outcomes in terms of a percentage change in the domain between pre- and post-intervention-whether objective or subjective-and the statistical significance of this change. Fourteen studies combined this with observation and six relied on observation alone to observe changes in knowledge, skills or practice [31, 38, 68-71]. In some cases, strengthened capacity through observation was rated as a percentage improvement [31], and in other cases, it was simply observed [57].
In terms of the time intervals across which capacity was assessed, most of the interventions $(n=28)$ assessed changes in capacity across short intervals, of around 1 week, ranging from 2.5 hours [57] to 2 days $(n=8)$ to 5 days $(n=8)$, and 6 to 8 days $(n=4)$; with others having intervals of several weeks or months $(n=17)$. These ranged from 1 month [56] up to 6 or $7(n=6)$ months, 18 months [72] and 4 years [43]. In four cases, domains were assessed a third time, after a period of some months, in order to assess the longer-term sustainability of the capacity strengthening intervention [52, 73]. For example, Blignault et al. [73] measured knowledge, attitudes and confidence via a pre- and post-workshop test, and measured attitudes and confidence 6 months later through a questionnaire on experience of learning in day-to-day practice. The degree or amount of capacity strengthened was primarily determined through a range of comparative and correlational analyses (i.e. $t$ tests/ ANOVAs, Chi-square, and regression analyses), manual content analysis, descriptive multi-variate and factor analysis, and difference-in-difference. Studies of high quality had strong conceptual frameworks and methodologies to guide the organisation and analysis of capacity strengthening.

\section{Discussion}

A common understanding of what is meant by 'strengthening capacity' for the primary health care workforce is needed, given their critical role in providing quality, person-centred health care. The importance of this common understanding is further reflected through the substantial investment in and focus on building primary health worker capacity in LMICs, as a key component of health systems strengthening. This scoping review therefore sought to synthesise the existing literature to determine how the concept of individual 'capacity strengthening' is operationalised and measured in practice, as an initial step towards building greater consensus around what is meant by the term 'capacity strengthening' for primary health care workers in LMICs.

The most salient domains identified in the sample were knowledge-included in all but four studies-and skills, followed by attitude, confidence, and practice. Overall, 
Table 3 Measurements of individual capacity strengthening

Objective 2: measurement of individual capacity strengthening

\begin{tabular}{ll}
\hline Measurement tool & Domains \\
\hline Pre-post learning assessment $(n=37)$ & Knowledge
\end{tabular}

Attitude

Knowledge, skills

Awareness (clinical), skills

Knowledge, self-efficacy

Knowledge, skills, commitment, resources

Knowledge, attitude, practice

Pre-post self-report measures $(n=21)$

Knowledge
Skills

Confidence

Self-efficacy

Knowledge, confidence

Knowledge, skills

Skills, self-efficacy

Attitude; practice

Self-efficacy, professional satisfaction

Knowledge, attitude, self-confidence

Knowledge, self-efficacy, motivation

Knowledge, skills, ability, confidence

Ability, leadership, motivation

Attitude, confidence, professional quality of life

Knowledge, attitude, practice, skills

Knowledge

Skills

Ability

Practice

Knowledge, skills

Knowledge, timeliness

Knowledge, practice

Practice, attitude

Skills, competencies

Interviews and/or focus group discussions ( $n=3)$

Knowledge, skills

Knowledge, Skills

Attitude

\section{Articles}

Abrahams-Gessel et al. [52]; Ameme et al. [65]; Bemah et al. [46]; Bikinesi et al. [41]; Chaoniyom et al. [53]; Citraningtyas et al. [29]; Crocker et al. [54]; Davila et al. [47]; Garg et al. [81]; HofmannBroussard et al. [48]; Kabir and Hossain [82]; Kohrt et al. [64]; Mazia et al. [56]; McConnell et al. [83]; Mehrotra et al. [49]; Merchant et al. [57]; Minh et al. [58]; Murugesan et al. [74]; Namazzi et al. [84]; Okereke et al. [85]; Oleribe et al. [86]; Pringle et al. [59]; Scheel et al. [37]; Sijbrandij et al. [50]; Soeters et al. [60]; Stephens et al. [61]; Tarannum et al. [36]; Tharkar et al. [62]; Wilson et al. [63]; Yu et al. [87]

Kohrt et al. [64]

Hien et al. [32]; Weaver et al. [34]

Oladele et al. [80]

Kamiru et al. [45]

Kim et al. [55]

Taieb et al. [66]; Spagnolo et al. [51]

Mehrotra et al. [49]; Sharma et al. [42]; Sennun et al. [67]

Perrone et al. [30]

Bemah et al. [46]; Hofmann-Broussard et al. [48]; Mehrotra et al. [49]; Sharma et al. [42]

Mehrotra et al. [49]; Spagnolo et al. [51]

Blignault et al. [73]

Dawson et al. [40]

Davila et al. [47]

Werdenberg et al. [72]

Bikinesi et al. [41]

Williams et al. [44]

Mutale et al. [39]

Edwards et al. [43]

Chaoniyom et al. [53]

Sijbrandij et al. [50]

Echeverri et al. [79]

Pringle et al. [59]; Soeters et al. [60]

Abrahams-Gessel et al. [52]; Bemah et al. [46]; Merchant et al. [57]; Namagembe et al. [31]; Scheel et al. [37]; Sijbrandij et al. [50]; Stephens et al. [61]; Tarannum et al. [36]; Wilson et al. [63]

Sennun et al. [67]

Burnett et al. [70], Minh et al. [58]

Asibon et al. [38]

André et al. [68]

Imani et al. [69]

Tharkar et al. [62]

Kohrt et al. [64]; Mazia et al. [56]

Crocker et al. [54]; Dawson et al. [40]

Kaewboonchoo et al. [33]

Cosimi et al. [35]

Hofmann-Broussard et al. [48]; Kamiru et al. [45]; Minh et al. [58] 
Table 3 (continued)

\begin{tabular}{lll}
\hline \multicolumn{2}{l}{ Objective 2: measurement of individual capacity strengthening } & \\
\hline Measurement tool & Domains & Articles \\
\hline $\begin{array}{ll}\text { Follow-up questionnaires } 6 \text { or } 12 \text { months later } \\
(n=5)\end{array}$ & Knowledge & Abrahams-Gessel et al. [52]; Namazzi et al. [84]; \\
& Oleribe et al. [86] \\
& $\begin{array}{l}\text { Skills } \\
\text { Knowledge, skills, attitude, confidence, profes- } \\
\text { sional quality of life }\end{array}$ & Sijbrandij et al. [50] \\
& & \\
\hline
\end{tabular}

only 20 studies in the review assessed the active implementation of objectives, through either observation or assessment of practical application. Consequently, our results suggest that the definition of capacity as "a measure of ability and, as most simply defined, capacity is the ability to carry out stated objectives" [18] is not systematically reflected in the operationalisation of capacity strengthening within the extant literature. Rather, our results suggest that capacity strengthening, where assessed, is largely operationalised as testing knowledge for action.

Capacity was predominantly measured using pre- and post-tests of knowledge change, with few studies tracing how improved knowledge translates into subsequent changes in practice. Of those studies that did assess how increased knowledge translates into practice, this was largely achieved through observation or practice assessments. Frequently, mechanisms to increase knowledge at individual level were simply assumed to lead to organisational-level capacity strengthening. For example, Murugesan et al. [74] built knowledge of doctors on diabetes care assuming this would lead to changes in their attitude and approach to chronic care of diseases and increase the national capacity for management of diabetes.

In addition to being deemed of higher quality, studies with more developed conceptual frameworks tended to frame capacity strengthening in broader and more comprehensive terms, that is, incorporating more than one domain and often across categories. Studies conceptualising capacity in this wider sense also tended to be informed by frameworks of capacity as broader development and aimed to strengthen each domain in a cohesive and stepwise manner. As an example, Chaoniyom et al. [53] strengthened the domain of motivation alongside knowledge, abilities and leadership. Other studies that employed broader frameworks of capacity included Davila et al. [47], who relied on experiential learning theory to inform their study design. Additionally, and while a 2017 systematic review of theoretical approaches to capacity strengthening [17] identified various theories related to capacity strengthening, we found no overlap between the review's sample and the present sample.
Overall, very few studies identified in the current study cited specific theories underpinning their approach.

Given the range of domains and measurements found in the literature, the common use of the term 'capacity', and the focus on strengthening health care systems within global health, we identify a need for a more defined description of what is, and what is not, considered 'capacity strengthening'. Notably, we argue that one domain is insufficient to be considered 'capacity strengthening' and encourage that going forward, the use of the term 'capacity strengthening' be reserved for broader, multi-faceted, interventions working across more than one domain. In this way, we recommend interventions addressing a single domain to simply use the terminology ascribed to the specific activity (i.e. increasing skills or improving knowledge, etc.) as a more accurate reflection of an intervention's impact, rather than using the broader term 'capacity strengthening'.

In light of our findings, we propose that individual capacity be better conceptualised in terms of a combination of domains that span technical ability, such as knowledge and skills; intra-personal domains, as domains internal to the individual, such as motivation and confidence; and inter-personal domains, such as leadership and management. These combinations can overlap in different ways, specific to each context, to offer a more comprehensive framework. Applying this framework to the current review, all 55 studies measured technical or clinical aspects of health care, 19 measured intra-personal aspects such as confidence, self-efficacy and attitude, and two measured inter-personal aspects of leadership and resources. Figure 2 offers a summary of this framework, whereby individual capacity building is conceptualised as a broader, more comprehensive and strategic model.

The domains identified in this review therefore reflect the three domains of learning, as identified within the educational literature (i.e. cognitive, affective and psychomotor) [75-77], whereby ability, practices and skills related to a technical capacity to perform a task or set of tasks (psychomotor); motivation, self-efficacy, confidence and commitment all related to an intra-personal capacity (affective); and 


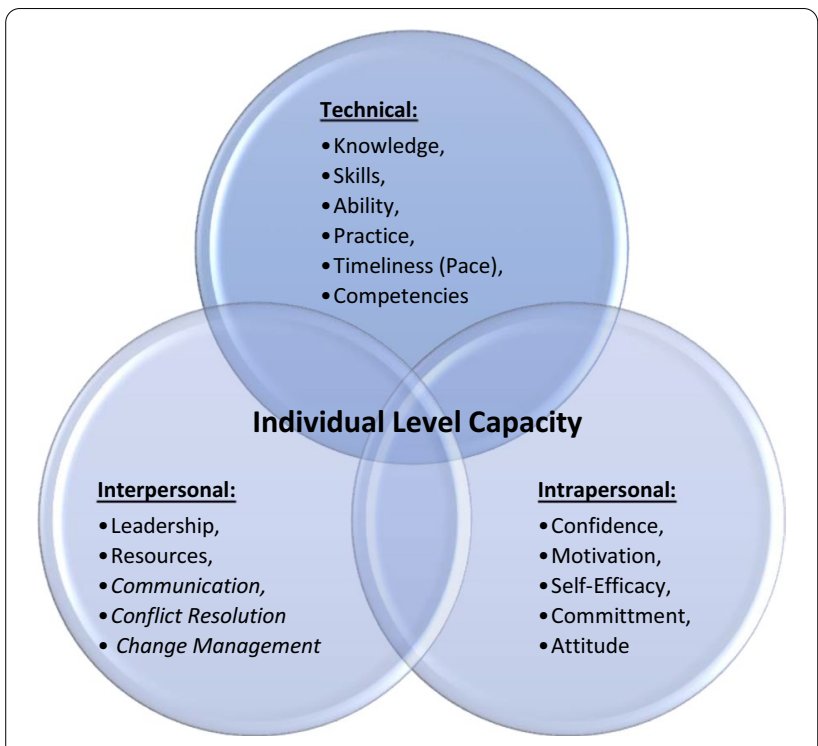

Fig. 2 Model of individual-level capacity strengthening

leadership and management related to an inter-personal capacity (cognitive). This new conceptualisation thus aligns with the literature on educational theories and other models and frameworks underpinning capacity strengthening interventions relevant to public health, for example, theories such as Diffusion of Innovations and Transformational Learning, and models such as Ecological and Interactive Systems Framework for Dissemination and Implementation [17]. We propose that initiatives to strengthen individual-level capacity and truly embed change within organisations and environments must therefore take into consideration the need to build capacity across these three spheres.

\section{Limitations}

The current study is not without limitations. Firstly, the study was limited by having one principal data extractor, though there was discussion of any cases, where necessary. Second, while we extracted domains in terms of how they were named in the articles, we acknowledge that these different terminologies may overlap in terms of their meaning. Third, and though we did include some search terms in French and Portuguese, studies were restricted only to the English language. Fourth, setting the cut-off year at 2000 might have resulted in the exclusion of studies that demonstrate earlier conceptualisations of capacity. Finally, while this review advances our understanding of what is meant by capacity strengthening within the literature, further research is required to test the validity of our proposed framework.

\section{Conclusion}

In the era of the Agenda 2030, Workforce 2030 and Universal Health Coverage, there is strong focus on strengthening capacities at individual, organisational and environmental levels. This study reviewed the evidencebase to identify salient domains of capacity at individual level, including how they are measured. The concept of capacity strengthening for primary health care reflected in a number of relevant frameworks and theories differs from what is commonly seen in practice, where capacity building is largely seen as knowledge increase and skills development. Conceptually however, capacity strengthening is more than knowledge acquisition. A conceptualisation of individual capacity strengthening across technical, intra-personal and inter-personal domains is proposed as a way to offer greater conceptual clarity and a more practical application of this concept in future work.

\section{Supplementary Information}

The online version contains supplementary material available at https://doi. org/10.1186/s12960-020-00547-y.

Additional file 1: Example search in MEDLINE (Ebsco).

Additional file 2: Data extraction tables.

Additional file 3: MMAT quality assessment scores.

Additional file 4: Pre-existing validated tools.

\section{Acknowledgements}

Not applicable.

\section{Authors' contributions}

MF and FV conceptualised the study. All authors contributed to the study design. GS conducted the database searching, with MF, FV and BG screening, extracting and synthesising data. MF led the manuscript preparation with FV and BG contributing to the initial draft. All authors contributed to manuscript revisions. All authors read and approved the final manuscript.

\section{Funding}

This paper is a product of PERFORM2Scale (2017-2021), a H2020 programme to strengthen management at district level in Ghana, Malawi and Uganda, in support of the achievement of Universal Health Coverage. The programme is funded by the European Union's Horizon 2020 research and innovation programme (Reference Number: 733360).

\section{Availability of data and materials}

All data extracted are presented in Additional file 2. Further details can be available from the corresponding author, Mairéad Finn, upon reasonable request.

Ethics approval and consent to participate Not applicable.

Consent for publication

Not applicable. 


\section{Competing interests}

The authors declare that they have no competing interests.

\section{Author details}

${ }^{1}$ Trinity Centre for Global Health, School of Psychology, Trinity College Dublin, Dublin, Ireland. ${ }^{2}$ Department of Public Health and Epidemiology, Royal College of Surgeons in Ireland, Dublin, Ireland. ${ }^{3}$ UCD Centre for Interdisciplinary Research, Education and Innovation in Health Systems, School of Nursing, Midwifery and Health Systems, University College Dublin, Dublin, Ireland. ${ }^{4}$ The Library of Trinity College Dublin, Dublin, Ireland.

Received: 10 July 2020 Accepted: 11 December 2020

Published online: 06 January 2021

\section{References}

1. DeCorby-Watson K, Mensah G, Bergeron K, Abdi S, Rempel B, Manson H. Effectiveness of capacity building interventions relevant to public health practice: a systematic review. BMC Public Health. 2018;18(1):684.

2. Swanson RC, Atun R, Best A, Betigeri A, de Campos F, Chunharas S, et al. Strengthening health systems in low-income countries by enhancing organizational capacities and improving institutions. Glob Health. 2015;11(1):5.

3. World Health Organization. Strengthening the health workforce to strengthen health systems. Geneva: World Health Organization; 2010

4. Alliance for Health Policy and Systems Research. Report of the expert consultation on primary care systems profiles \& performance (PRIMASYS). Geneva: World Health Organisation; 2015.

5. Yeager VA, Bertrand J. Putting management capacity building at the forefront of health systems strengthening: Comment on "Management Matters: A Leverage Point for Health Systems Strengthening in Global Health." Int J Health Policy Manage. 2015;5(2):129-31.

6. World Health Organization. Global Strategy on Human Resources for Health: Workforce 2030. Geneva: World Health Organization; 2016.

7. United Nations General Assembly. Transforming our world: the 2030 agenda for sustainable development. New York: United National Department of Economic and Social Affairs; 2015.

8. Goodman RM, Speers MA, McLeroy K, Fawcett S, Kegler M, Parker E, et al. Identifying and defining the dimensions of community capacity to provide a basis for measurement. Health Educ Behav. 1998;25(3):258-78

9. Horton D, Alexaki A, Bennet-Lartey S. Evaluating capacity development: experiences from research development organizations around the world. The Hague: International Service for National Agricultural Research/International Development Research Centre; 2003.

10. PEPFAR. Capacity building and strengthening framework. Washington D.C.: U.S. State Department President's Emergency Plan for AIDS Relief; 2012.

11. UNDP. Capacity development: a UNDP primer. New York: United Nations Development Programme Capacity Development Group; 2009.

12. Morel T, Maher D, Nyirenda T, Olesen OF. Strengthening health research capacity in sub-Saharan Africa: mapping the 2012-2017 landscape of externally funded international postgraduate training at institutions in the region. Globalization and Health. 2018;14(1):77

13. Dean L, Gregorius S, Bates I, Pulford J. Advancing the science of health research capacity strengthening in low-income and middle-income countries: a scoping review of the published literature, 2000-2016. BMJ Open. 2017;7(12):e018718.

14. Banek K, Nankabirwa J, Maiteki-Sebuguzi C, Diliberto D, Taaka L, Chandler $\mathrm{Cl}$, et al. Community case management of malaria: exploring support, capacity and motivation of community medicine distributors in Uganda. Health Policy Plann. 2014

15. Liberato SC, Brimblecombe J, Ritchie J, Ferguson M, Coveney J. Measuring capacity building in communities: a review of the literature. BMC Public Health. 2011;11(1):850.

16. Crisp BR, Swerissen H, Duckett SJ. Four approaches to capacity building in health: consequences for measurement and accountability. Health Promot Int. 2000;15(2):99-107.

17. Bergeron K, Abdi S, DeCorby K, Mensah G, Rempel B, Manson H. Theories, models and frameworks used in capacity building interventions relevant to public health: a systematic review. BMC Public Health. 2017;17(1):914.
18. Aroni A. Health management capacity building: an integral component of health systems' improvement. Brussels: European Health Management Association; 2012

19. Ebbesen LS, Heath S, Naylor P-J, Anderson D. Issues in measuring health promotion capacity in Canada: a multi-province perspective. Health Promot Int. 2004;19(1):85-94.

20. Arksey H, O'Malley L. Scoping studies: towards a methodological framework. Int J Soc Res Methodol. 2005;8(1):19-32.

21. Levac D, Colquhoun H, O'Brien KK. Scoping studies: advancing the methodology. Implement Sci. 2010;5(1):69.

22. Munn Z, Peters MD, Stern C, Tufanaru C, McArthur A, Aromataris E. Systematic review or scoping review? Guidance for authors when choosing between a systematic or scoping review approach. BMC Med Res Methodol. 2018;18(1):143.

23. International Conference on Primary Health Care. Declaration of AlmaAta. WHO Chron. 1978;32(11):428-30.

24. World Health Organization and UNICEF. A Vision for Primary Health Care in the 21st Century: Towards Universal Health Coverage and the Sustainable Development Goals. Geneva: World Health Organization and the United Nations Children's Fund (UNICEF); 2018.

25. Bowsher G, Papamichail A, El Achi N, Ekzayez A, Roberts B, Sullivan R, et al. A narrative review of health research capacity strengthening in low and middle-income countries: lessons for conflict-affected areas. Glob Health. 2019;15(1):23

26. World Bank. World Development Indicators. 2019.

27. Pluye P, Hong QN. Combining the power of stories and the power of numbers: mixed methods research and mixed studies reviews. Annu Rev Public Health. 2014;35(1):29-45.

28. Tagoe N, Molyneux S, Pulford J, Murunga VI, Kinyanjui S. Managing health research capacity strengthening consortia: a systematised review of the published literature. BMJ Global Health. 2019;4(2):e001318.

29. Citraningtyas T, Martina W, Nurmiati A, Hervita D, Tjhin W. Capacity building for child and adolescent mental health in disaster areas: learning from the experiences of mental health care workers in Indonesia. Aust J Disast Trauma Stud. 2017;21(2):57-64.

30. Perrone LA, Confer D, Scott E, Livingston L, Bradburn C, McGee A, et al. Implementation of a mentored professional development programme in laboratory leadership and management in the middle east and North Africa. Eastern Mediterranean Health J. 2016;22(11):832-9.

31. Namagembe A, Ssekabira U, Weaver MR, Blum N, Burnett S, Dorsey G, et al. Improved clinical and laboratory skills after team-based, malaria case management training of health care professionals in Uganda. Malar J. 2012;11:44.

32. Hien LTT, Takano T, Seino K, Ohnishi M, Nakamura K. Effectiveness of a capacity-building program for community leaders in a healthy living environment: a randomized community-based intervention in rural Vietnam. Health Promot Int. 2008;23(4):354-64.

33. Kaewboonchoo $O$, Silpasuwan $P$, Jirapongsuwan $A$, Rawiworrakul T, Hansing S. Participatory capacity building in occupational disease surveillance among primary care unit (PCU) health personnel. Southeast Asian J Trop Med Public Health. 2011;42(5):1262-8.

34. Weaver MR, Crozier I, Eleku S, Makanga G, Mpanga Sebuyira L, Nyakake J, et al. Capacity-building and clinical competence in infectious disease in Uganda: a mixed-design study with pre/post and cluster-randomized trial components. PLoS ONE. 2012;7(12):e51319.

35. Cosimi LA, Dam HV, Nguyen TQ, Ho HT, Do PT, Duc DN, et al. Integrated clinical and quality improvement coaching in Son La Province, Vietnam: a model of building public sector capacity for sustainable HIV care delivery. BMC Health Serv Res. 2015;15:269.

36. Tarannum S, Elshazly M, Harlass S, Ventevogel P. Integrating mental health into primary health care in Rohingya refugee settings in Bangladesh: experiences of UNHCR. Intervention. 2019:17(2):130-9.

37. Scheel JR, Peacock S, Orem J, Bugeza S, Muyinda Z, Porter PL, et al. Improving breast ultrasound interpretation in Uganda using a condensed breast imaging reporting and data system. Acad Radiol. 2016:23(10):1271-7.

38. Asibon A, Lufesi N, Choudhury A, Olvera S, Molyneux E, Oden M, et al. Using a peer mentorship approach improved the use of neonatal continuous positive airway pressure and related outcomes in Malawi. Acta Paediatr. 2020;109(4):705-10. 
39. Mutale W, Vardoy-Mutale AT, Kachemba A, Mukendi R, Clarke K, Mulenga D. Leadership and management training as a catalyst to health system strengthening in low-income settings: Evidence from implementation of the Zambia Management and Leadership course for district health managers in Zambia. PLoS ONE. 2017;12(7):e0174536.

40. Dawson A, Kililo M, Geita L, Mola G, Brodie PM, Rumsey M, et al. Midwifery capacity building in Papua New Guinea: key achievements and ways forward. Women Birth. 2016;29(2):180-8.

41. Bikinesi L, O'Bryan G, Roscoe C, Mekonen T, Shoopala N, Mengistu AT, et al. Implementation and evaluation of a Project ECHO telementoring program for the Namibian HIV workforce. Hum Resour Health. 2020;18(1):61.

42. Sharma A, Jose AP, Pandey N, Vats S, Bagre V, Kumar H, et al. A collaborative model for capacity building of primary care physicians in the management of Hypertension in India. J Hum Hypertens. 2019;33(8):562-5.

43. Edwards N, Kaseje D, Kahwa E, Klopper HC, Mill J, Webber J, et al. The impact of leadership hubs on the uptake of evidence-informed nursing practices and workplace policies for HIV care: a quasi-experimental study in Jamaica, Kenya, Uganda and South Africa. Implement Sci. 2016:11(1):110.

44. Williams AB, Le ST, Colby D, Le Thu TT, PollackT, Cosimi L. Effectiveness of train-the-trainer HIV education: a model from Vietnam. J Assoc Nurses AIDS Care. 2014;25(4):341-50

45. Kamiru HN, Ross MW, Bartholomew LK, McCurdy SA, Kline MW. Effectiveness of a training program to increase the capacity of health care providers to provide HIV/AIDS care and treatment in Swaziland. AIDS Care. 2009;21(11):1463-70.

46. Bemah P, Baller A, Cooper C, Massaquoi M, Skrip L, Rude JM, et al. Strengthening healthcare workforce capacity during and post Ebola outbreaks in Liberia: an innovative and effective approach to epidemic preparedness and response. Pan Afr Med J. 2019;33(Suppl 2):9.

47. Davila EP, Suleiman Z, Mghamba J, Rolle I, Ahluwalia I, Mmbuji P, et al. Non-communicable disease training for public health workers in lowand middle-income countries: lessons learned from a pilot training in Tanzania. Int Health. 2015;7(5):339-47.

48. Hofmann-Broussard C, Armstrong G, Boschen MJ, Somasundaram KV. A mental health training program for community health workers in India: impact on recognition of mental disorders, stigmatizing attitudes and confidence. Int J Cult Ment Health. 2017;10(1):62-74.

49. Mehrotra K, Chand P, Bandawar M, Rao Sagi M, Kaur S, Aurobind G, et al. Effectiveness of NIMHANS ECHO blended tele-mentoring model on Integrated Mental Health and Addiction for counsellors in rural and underserved districts of Chhattisgarh, India. Asian J Psychiatr. 2018;36:123-7.

50. Sijbrandij M, Horn R, Esliker R, O'May F, Reiffers R, Ruttenberg L, et al. The effect of psychological first aid training on knowledge and understanding about psychosocial support principles: a cluster-randomized controlled trial. Int J Environ Res Public Health. 2020;17(2):484.

51. Spagnolo J, Champagne F, Leduc N, Rivard M, Melki W, Piat M, et al. Building capacity in mental health care in low- and middle-income countries by training primary care physicians using the mhGAP: a randomized controlled trial. Health Policy Plan. 2020;35(2):186-98.

52. Abrahams-Gessel S, Denman CA, Montano CM, Gaziano TA, Levitt $\mathrm{N}$, Rivera-Andrade A, et al. The training and fieldwork experiences of community health workers conducting population-based, noninvasive screening for CVD in LMIC. Global Heart. 2015;10(1):45-54.

53. Chaoniyom W, Suwannapong N, Howteerakul N, Pacheun O. Strengthening the capability of family health leaders for sustainable communitybased health promotion. Southeast Asian J Trop Med Public Health. 2005;36(4):1039-47.

54. Crocker J, Shields KF, Venkataramanan V, Saywell D, Bartram J. Building capacity for water, sanitation, and hygiene programming: Training evaluation theory applied to CLTS management training in Kenya. Soc Sci Med. 2016;166:66.

55. Kim JM, Koh KW, Oak CH, Jung WH, Kim SH, Park DH. Assessment of village health worker training program in Tuguegarao, Philippine. J Prev Med Public Health. 2009;42(6):377-85.

56. Mazia G, Narayanan I, Warren C, Mahdi M, Chibuye P, Walligo A, et al. Integrating quality postnatal care into PMTCT in Swaziland. Glob Public Health. 2009;4(3):253-70.

57. Merchant A, Outhay M, Gonzaléz-Calvo L, Moon TD, Sidat M, Taibo CLA, et al. Training laypersons and hospital personnel in basic resuscitation techniques: an approach to impact the global trauma burden in Mozambique. World J Surg. 2015;39(6):1433-7.

58. Minh PD, Huong DTM, Byrkit R, Murray M. Strengthening pharmacy practice in Vietnam: findings of a training intervention study. Trop Med Int Health. 2013;18(4):426-34

59. Pringle K, Mackey JM, Modi P, Janeway H, Romero T, Meynard F, et al. A short trauma course for physicians in a resource-limited setting: Is lowcost simulation effective? Injury. 2015;46(9):1796-800.

60. Soeters HM, Koivogui L, de Beer L, Johnson CY, Diaby D, Ouedraogo A, et al. Infection prevention and control training and capacity building during the Ebola epidemic in Guinea. PLoS ONE. 2018;13(2):e0193291.

61. Stephens T, De Silva AP, Beane A, Welch J, Sigera C, De Alwis S, et al. Capacity building for critical care training delivery: Development and evaluation of the Network for Improving Critical Care Skills Training (NICST) programme in Sri Lanka. Intensive Crit Care Nurs. 2017;39:28-36.

62. Tharkar S, Kathiresan K, Abraham P, Viswanathan V. Development and evaluation of a training programme on primary prevention of diabetes for primary care physicians. Int J Health Res. 2009;2(4):307-14.

63. Wilson E, Lee L, Klas R, Nesbit KC. Technology and rehabilitation training for community health workers: Strengthening health systems in Malawi. Health Soc Care Community. 2020;28(3):833-41.

64. Kohrt BA, Turner EL, Rai S, Bhardwaj A, Sikkema KJ, Adelekun A, et al. Reducing mental illness stigma in healthcare settings: proof of concept for a social contact intervention to address what matters most for primary care providers. Soc Sci Med. 2020;250:112852.

65. Ameme DK, Nyarko KM, Afari EA, Antara S, Sackey SO, Wurapa F. Training Ghanaian frontline healthcare workers in public health surveillance and disease outbreak investigation and response. Pan Afr Med J. 2016;25:2.

66. Taieb F, Dub T, Madec Y, Tondeur L, Chippaux JP, Lebreton M, et al. Knowledge, attitude and practices of snakebite management amongst health workers in Cameroon: Need for continuous training and capacity building. PLoS Negl Trop Dis. 2018;12(10):e0006716-e.

67. Sennun P, Suwannapong N, Howteerakul N, Pacheun O. Participatory supervision model: building health promotion capacity among health officers and the community. Rural Remote Health. 2006;6(2):440.

68. André AM, Lopez A, Perkins S, Lambert S, Chace L, Noudeke N, et al. Frontline field epidemiology training programs as a strategy to improve disease surveillance and response. Emerg Infect Dis. 2017;23(13):S166-73.

69. Imani P, Jakech B, Kirunda I, Mbonye MK, Naikoba S, Weaver MR. Effect of integrated infectious disease training and on-site support on the management of childhood illnesses in Uganda: a cluster randomized trial. BMC Pediatrics. 2015;15:103.

70. Burnett SM, Mubiru N, Imani P, Mbonye MK, Fisher L, Colebunders R, et al. Synergistic impact of training followed by on-site support on HIV clinical practice: a mixed-design study in Uganda with pre/post and cluster-randomized trial components. J Acquir Immune Defic Syndr. 2018;77(5):467-75

71. Al Shdaifat A, Zink T. Pilot study to build capacity for family medicine with abbreviated, low-cost training programme with minimal impact on patient care for a cohort of 84 general practitioners caring for Palestinian refugees in Jordan. BMJ Open. 2019;9(8):e028240.

72. Werdenberg J, Biziyaremye F, Nyishime M, Nahimana E, Mutaganzwa C, Tugizimana D, et al. Successful implementation of a combined learning collaborative and mentoring intervention to improve neonatal quality of care in rural Rwanda. BMC Health Serv Res. 2018;18(1):941.

73. Blignault I, Manicavasagar V, Parker G, Wijeratne C, Sumathipala A. Building capacity in identification and management of mood disorders: an Australia-Sri Lanka collaboration. Australas Psychiatry. 2012;20(1):53-6.

74. Murugesan N, Shobana R, Snehalatha C, Kapur A, Ramachandran A. Immediate impact of a diabetes training programme for primary care physicians - an endeavour for national capacity building for diabetes management in India. Diabetes Res Clin Pract. 2009;83(1):140-4.

75. Adams NE. Bloom's taxonomy of cognitive learning objectives. J Med Libr Assoc. 2015;103(3):152-3.

76. Légaré F, Freitas A, Thompson-Leduc P, Borduas F, Luconi F, Boucher $A$, et al. The majority of accredited continuing professional development activities do not target clinical behavior change. Acad Med. 2015;90(2):197-202.

77. Bloom B. Taxonomy of educational objectives: the classification of education goals. New York: Longman Green; 1956. 
78. Liautaud A, Adu PA, Yassi A, Zungu M, Spiegel JM, Rawat A, et al. Strengthening human immunodeficiency virus and tuberculosis prevention capacity among South African healthcare workers: a mixed methods study of a collaborative occupational health program. Saf Health Work. 2018;9(2):172-9.

79. Echeverri C, Le Roy J, Worku B, Ventevogel P. Mental health capacity building in refugee primary health care settings in Sub-Saharan Africa: impact, challenges and gaps. Glob Ment Health. 2018;5:e28.

80. Oladele RO, Jordan A, Akande P, Akanmu SA, Akase IE, Aliyu S, et al. Tackling cryptococcal meningitis in Nigeria, one-step at a time; the impact of training. PLoS ONE. 2020;15(7):e0235577.

81. Garg S, Basu S, Baswal D, Mariram W, Rustagi R. Training of health workers for Maternal Death Surveillance and Response program in India: knowledge assessment and analytical evaluation. J Midwifery Reprod Health. 2020;8(1):2041-9.

82. Kabir H, Hossain S. Knowledge on leprosy and its management among primary healthcare providers in two districts of Bangladesh. BMC Health Serv Res. 2019;19(1):787.

83. McConnell KA, Krisher LK, Lenssen M, Bunik M, Bunge Montes S, Domek GJ. Telehealth to expand community health nurse education in rural Guatemala: a pilot feasibility and acceptability evaluation. Front Public Health. 2017;5:60
84. Namazzi G, Waiswa P, Nakakeeto M, Nakibuuka VK, Namutamba S, Najjemba M, et al. Strengthening health facilities for maternal and newborn care: experiences from rural eastern Uganda. Glob Health Action. 2015;8:24271.

85. Okereke E, Tukur J, Oginni AB, Obonyo B. Evaluating health workers' knowledge following the introduction of clinical mentoring in Jigawa State, Northern Nigeria. Afr J Reprod Health. 2015;19(3):1 18-25.

86. Oleribe OO, Salako BL, Akpalu A, Anteyi E, Ka MM, Deen G, et al. Public private partnership in in-service training of physicians: the millennium development goal 6-partnership for African clinical training (M-PACT) approach. Pan Afr Med J. 2018;29:77.

87. Yu X, Pendse A, Slifko S, Inman AG, Kong P, Knettel BA. Healthy people, healthy community: evaluation of a train-the-trainers programme for community health workers on water, sanitation and hygiene in rural Haiti. Health Educ J. 2019;78(8):931-45.

\section{Publisher's Note}

Springer Nature remains neutral with regard to jurisdictional claims in published maps and institutional affiliations.
Ready to submit your research? Choose BMC and benefit from:

- fast, convenient online submission

- thorough peer review by experienced researchers in your field

- rapid publication on acceptance

- support for research data, including large and complex data types

- gold Open Access which fosters wider collaboration and increased citations

- maximum visibility for your research: over $100 \mathrm{M}$ website views per year

At BMC, research is always in progress.

Learn more biomedcentral.com/submissions 